\title{
Prediction model of cyclist's accident probability in the City of Malang
}

\author{
Imma Widyawati Agustin ${ }^{1, *}$, Muhammad Zainul Arifin ${ }^{2}$ \\ ${ }^{1}$ Brawijaya University, Depart. of Urban and Regional Planning, Malang, East Java, Indonesia \\ ${ }^{2}$ Brawijaya University, Depart. of Civil Engineering, Malang, East Java, Indonesia
}

\begin{abstract}
The development of transport is currently very rapid. This is because the increasing needs of the community, is directly proportional to the needs of public transport modes need to be able to support their activities. Malang is the second largest city in East Java province that has transportation problems such as traffic jams and high accident rate. The main purpose of the research is to create prediction model of cyclists' accident probability in the City of Malang. The research used frequency analysis and logistic regression analysis. The results showed that The prediction model of cyclists' accidents involving bicycle users in the City of Malang was formulated with $P=$ $\frac{1}{1+e^{-\left(-1.047+1.103 x_{3}+1,617 x_{6}-1.965 x_{15}+2.029 x_{16}+1.057 x_{24}\right)}}$ with $\mathrm{X}_{3}=$ income, $\mathrm{X}_{6}=$ ownership of bicycle, $\mathrm{X}_{15}=$ behavior of check the brakes, $\mathrm{X}_{16}=$ behavior of check the tires, and $\mathrm{X}_{24}=$ cycling in groups.
\end{abstract}

\section{Introduction}

Traffic accidents according to the Law Number 22 [1] on The Road Traffic and Transportation is an unexpected and accidental incident on roads involving vehicles with or without other road users that result in human casualties and or loss of property. Accidents are influenced by several factors, including human factors, vehicle factors, road factors and environmental factors. Accidents due to human factors are influenced by the individual characteristics of the rider. Vehicle factors are affected by the reliability conditions of the components in the vehicle to maneuver when the vehicle is moving. Road factors are influenced by road infrastructure conditions that support comfort, safety and security in driving. While environmental factors are influenced by the bad weather around the crash site that can affect the driver's visibility in driving [2]. Accidents involving cyclists in Malang are 4 cases in 2014 - 2015 and in 2016 decreased to 3 cases of accidents. Generally cases of bicycle accidents in the city of Malang is happening on the road that does not have a special lane bicycle. Based on accident data from the police at least almost all road functions such as arterial road, collector, and environment there are cases of bicycle accidents [3].

The socio-economic characteristics of cyclist have an influence on bicycle ownership, movement characteristics, and behavior of cyclist. In this study the discussion of socio-

\footnotetext{
${ }^{*}$ Corresponding author: immasaitama@ub.ac.id
} 
economic characteristics of cyclist includes age, gender, education, occupation, and income [4]. The movement was formed as a result of the activities carried out not in residence. This means that the relationship between the regions is instrumental in creating a space travel and distribution patterns of land use affect the travel patterns of people [5]. Characteristics of movement in this study focus on Purpose of movement, Distance, Travel time, Intensity of use, Start time activity [6]. Sulistio et al. [7] explains that the characteristics of riders based on their behavior are differentiated into driving preparation, driving attitude, driving experience, driving care, and knowledge in driving.

There are several problems related to cyclist accident in the City of Malang, traffic condition mixed between motorized and non-motorized vehicles so that all types of vehicles move together in the same lane or not separate. In addition there are many cyclists who do not use cycling safety equipment such as bicycle helmets (Figure 1a). Roads that currently operate are many that are incompatible with the hierarchy of road functions, especially for bike lanes where often these lanes are used by motor vehicles and used for other activities (Figure 1b). Cyclist behavior that could endanger the safety of themselves and motorists in the vicinity such as carrying cargo in bulk (Figure 1c).

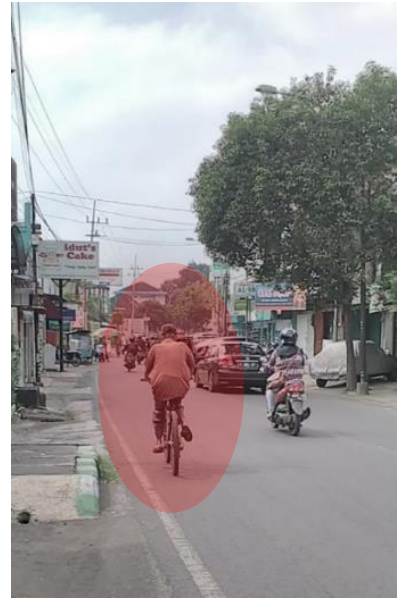

(a)

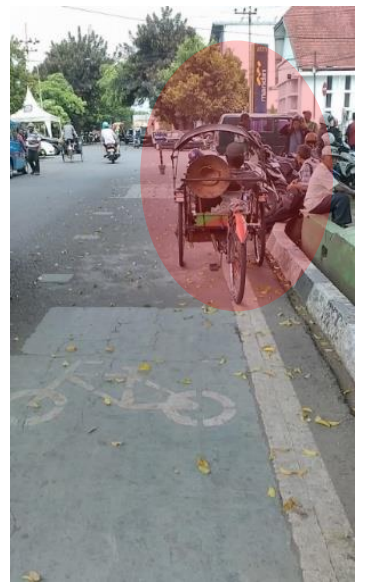

(b)

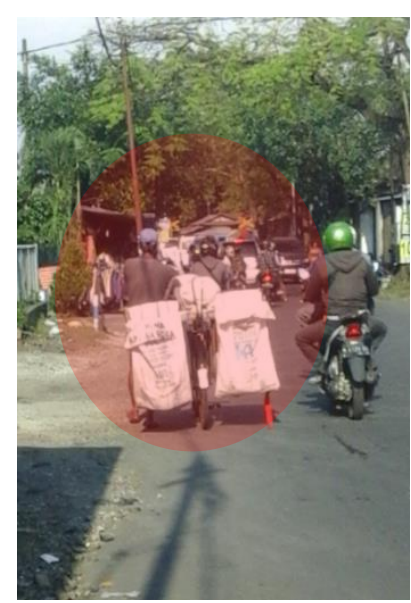

(c)

Fig. 1. Some problems related to bicycle accident

Sources: Field survey, 2017

\section{Methods}

Model predictions accident opportunities in this study is a model developed to predict the chances of an accident that might occur in the future, with the variables used in this study is the characteristics of cyclist such as socio-economic characteristics, the characteristics of the movement, and behavioral characteristics. The characteristics of cyclists' accidents in this study were based on the experience of accidents during cycling that had been experienced by cyclist in the study area.

This research consists of several stages, firstly: the preparation stage. In this preparation stage, literature study is used as reference in the implementation of the study. It also determined the purpose of the study undertaken, as well as determine the related objects to be used for research. The second stage is the collection of data in the form of primary data and secondary data that support the study. Primary data were obtained from distributing questionnaires to respondents, interviews to interviewees and field surveys. While the secondary data obtained from related agencies such as the Regional Development Planning 
Board in Malang, Transportation Department, Public Works Department, East Java Regional Police, Central Bureau of Statistics, and others. The third stage is the data analysis required in accordance with the purpose of the study that has been determined. Data analysis was done in the form of descriptive analysis of the variables obtained from the primary data and secondary data, and logistic regression analysis to create an accident probability model that can occur. The last stage is the preparation of the discussion and conclusions on the results of studies that have been done (Figure 2).

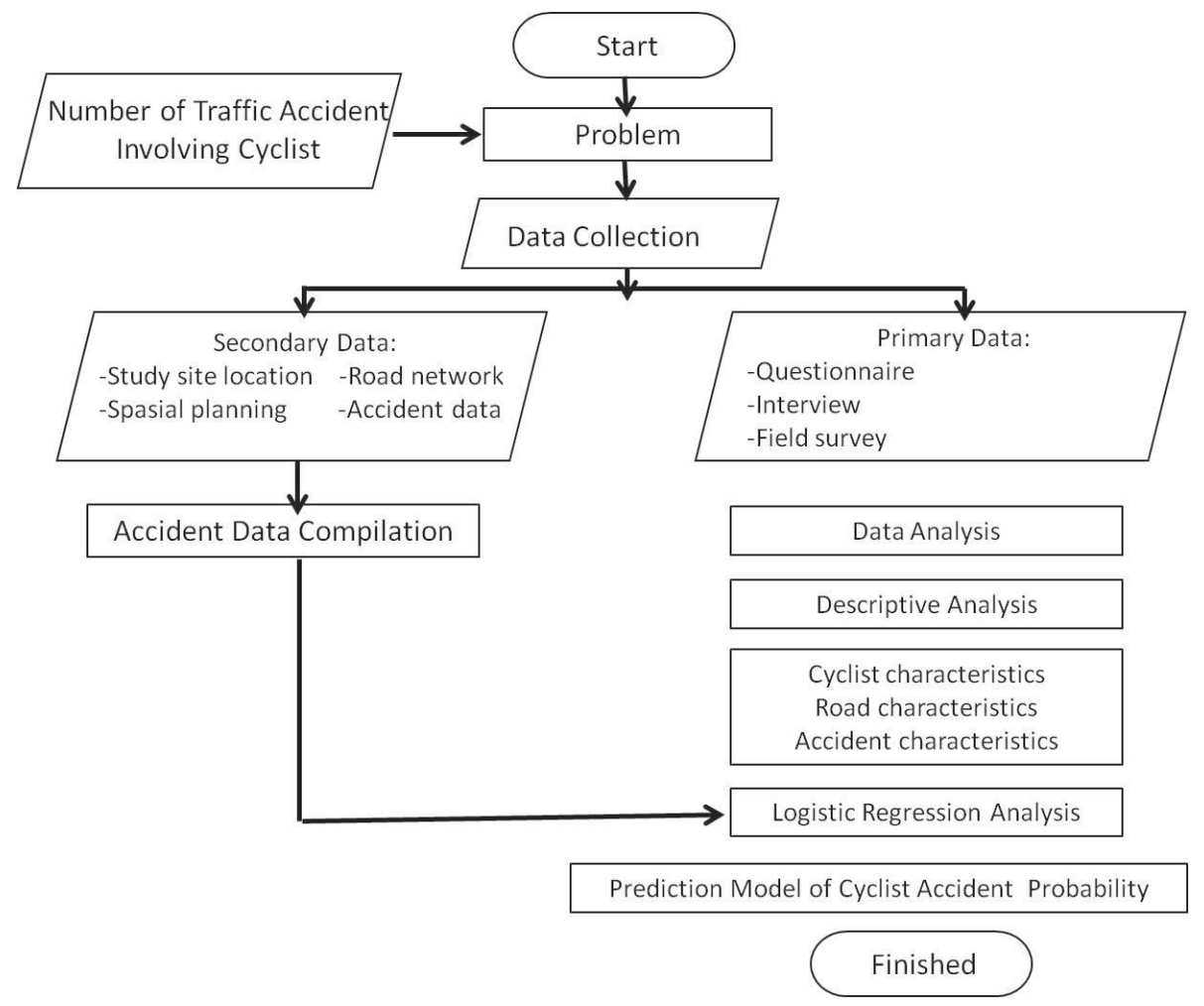

Fig. 2. Research framework

The stages taken to create a chance model of accidents are the determination of the respondent, in case the respondent is a cyclist in the study area who has been actively cycling once in the past 6 months. From the distribution of questionnaires in the study area then the data input into the SPSS program to then be tested between each explanatory variables with the variable response (univariate correlation) in this case is conducted by enter method in SPSS program. This identification is conducted by Chi Square Test, where each variable will be tested one by one to know whether the variable has an effect on the chance of having an accident.

The independent variables that have been shown to have significant effect will be reprocessed by the Wald Test. The variables in the study will be tested as a whole for the next estimation of a logistic model that aims to select the variables that have a significant effect on the chance of having an accident (Figure 3). This method works by issuing one by one variable that proved not significant (significance more than 0.05 ). 


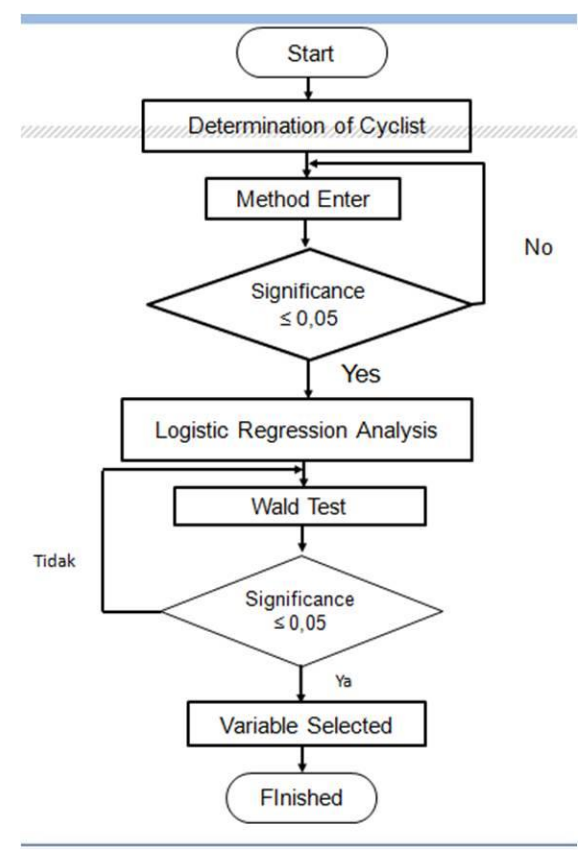

Fig. 3. Logistic regression analysis

According to Sulistio et al [7] the establishment of a logit model is based on the function of logistical opportunity that is specified as follows:

$$
P_{i}=F\left(\beta_{0}+\beta_{1} X_{1 i}\right)=\frac{1}{1+e^{-z}}=\frac{1}{1+e^{-\left(\beta_{0}+\beta_{1} X_{l i}\right)}} .
$$

Furthermore, based on the formation of logit model according to Sulistio et al [7], the model structure used in this study is as follows:

$$
P_{(B A)}=\frac{1}{1+e^{-\left(\beta_{0}+\beta_{1} x_{1}+\beta_{2} x_{2}+\beta_{3} x_{3}+\cdots\right)}}
$$

Information:

$\mathrm{P}_{(\mathrm{BA})} \quad=$ chance of bicycle accident occurrence

$\mathrm{e}=$ natural number $(2,71828)$

$\beta=$ explanatory variable coefficient (predictor)

$\mathrm{X}=$ explanatory variable (predictor)

\section{Results and discussion}

\subsection{Characteristic of cyclist}

Characteristics of cyclists based on socio-economic in the study area of Malang City conducted to 100 cyclists, obtained the following results:

- The age of majority of cyclists is 15-25 years old in the study area and the majority is male.

- The majority of cyclists have a recent education level of Senior High School / Vocational High School / Madrasah Aliyah, working as a student.

- Income of cyclists is around Rp.1.000.000 to Rp.2.000.000. 
The majority of bicycle ownership is owned by themselves with 1 bicycle ownership. As for other vehicles, the majority of cyclists have motorcycles.

Table 1. Recapitulation of socio economic characteristic of cyclist in the City of Malang

\begin{tabular}{|c|c|c|}
\hline Characteristics of Socio Economic & Results & Percentage (\%) \\
\hline Gender & Male & 73 \\
\hline Age & $15-25$ years old & 48 \\
\hline Education & SMU/SMK/MA & 48 \\
\hline Occupation & Student & 47 \\
\hline Income & Rp. 1.000 .000 - Rp. & 29 \\
\hline Ownership of bicycles & Owned by themselves & 90 \\
\hline Ownership of bike & 1 & 63 \\
\hline Amount of ownership & Motorcycle & 57 \\
\hline
\end{tabular}

Characteristics of cyclists based on movement are as follows:

- The majority of cyclists in Malang City use bicycles for sport purpose.

- The distance traveled by the majority of cyclists in the city of Malang is less than $5 \mathrm{~km}$ with travel time less than 30 minutes.

- The intensity of bicycle use by respondents for the study area of Malang City is uncertain.

Table 2. Recapitulation of movement characteristic of cyclist in the City of Malang

\begin{tabular}{|c|c|c|}
\hline Characteristics of Movement & Results & Percentage (\%) \\
\hline Purpose and objective & Sport & 28 \\
\hline Distance & $<5 \mathrm{~km}$ & 66 \\
\hline Travel time & $<30$ minutes & 53 \\
\hline Intensity of use & uncertain & 32 \\
\hline Start time activity & $06.01-08.00 \mathrm{am}$ & 61 \\
\hline
\end{tabular}

Based on behavioral aspects, the majority of cyclists in the City of Malang never check the bicycle lights, always check the condition of the brakes and bicycle tires and sometimes check the condition of the bicycle chain. While on driving, the majority of cyclists in Malang never wear helmets, never wear gloves, never wear elbow protector and never wear a knee protector. In addition, when driving, the majority of cyclists in the city of Malang also never rode ("berboncengan"), never cycling in groups, never frolic, do not break through the red light and never carry more goods / payload. From the analysis results also found that cyclists in Malang City sometimes wear brightly colored clothing while driving, sometimes preceding ("menyiap") another vehicle from the right, sometimes traveling when it rains and always give a sign when going to turn right (Table 3). 
Table 3. Recapitulation of behavior characteristic of cyclist in the City of Malang

\begin{tabular}{|l|c|c|}
\hline \multicolumn{1}{|c|}{ Focus } & Results & Percentage (\%) \\
\hline Behavior before cycling & & 52 \\
\hline Check the condition of the bike lights & never & 45 \\
\hline Check the condition of the bicycle brake & always & 60 \\
\hline Check the condition of the bicycle tire & always & 41 \\
\hline Check the condition of the bicycle chain & occasionally & \\
\hline Behavior while cycling & & 61 \\
\hline Wear a helmet & never & 62 \\
\hline Wearing gloves & never & 78 \\
\hline Wear a knee protector & never & 81 \\
\hline Wear protective elbows & never & 51 \\
\hline Wear bright / bright clothing & occasionally & 81 \\
\hline Rode ("Berboncengan") & never & 53 \\
\hline Cycling in groups & never & 56 \\
\hline Frolic & never & 79 \\
\hline Break through the red light & never & 79 \\
\hline Bringing goods / cargo in large quantities & never & 47 \\
\hline $\begin{array}{l}\text { Preceding ("menyiap") another vehicle from the } \\
\text { right }\end{array}$ & occasionally & 42 \\
\hline Marking when it will turn right & never & 49 \\
\hline Traveling by bicycle in the rain & occasionally & \\
\hline
\end{tabular}

The characteristics of cyclist accident in the study area of Malang City are as follows:

- The majority of cyclist in the City of Malang had experienced accidents while cycling that is equal to 61 people from 100 cyclists.

- The disadvantages of accident costs in this study are differentiated from cost loss due to injury treatment and cost loss due to bicycle repair. The majority of cyclist in the City of Malang suffered losses due to costs of injury and loss costs due to bicycle repair for less than Rp. 50,000.

- The majority of bicycle accidents that happened to cyclists in the study area of Malang occurred in the afternoon with the majority of causes of accidents due to slippery or damaged roads.

\subsection{Prediction model of cyclist accident probability}

Prediction model of cyclist accident probability based on the resulting socio-economic aspects are:

$$
P_{(B A)}=\frac{1}{1+e^{-\left(0,844+1,128 x_{3}-1,491 x_{4}\right)}}
$$

Prediction model of cyclists' accidents probability based on socio-economic characteristics in the City of Malang is influenced by $\mathrm{X}_{3}$ (education) and $\mathrm{X}_{4}$ (occupation).

Example calculation:

$$
P_{(B A)}=\frac{1}{1+e^{-(0,844+1,128(1)-1,491(0))}}=0,783
$$

Based on the example can be interpreted if the chance of accidents bike users in Malang based on socio-economic characteristics influenced by the level of education and work. 
Bicycle users with education other than Senior High School/Madrasah Aliyah (MA)/Vocational High School and work as a student / students have an accident of 78.3 per cent.

Prediction model of cyclist accident probability based on movement aspects are:

$$
P_{(B A)}=\frac{1}{1+e^{-\left(1,386-1,272 x_{12}\right)}}
$$

Prediction model of cyclists' accidents probability based on movement characteristics in the City of Malang is influenced by $\mathrm{X}_{12}$ (intensity of bicycle use).

Example calculation:

$$
P_{(B A)}=\frac{1}{1+e^{-(1,386-1,272(0))}}=0,800
$$

Based on the example can be interpreted if the chance of cyclists' accidents in Malang City based on the characteristics of the movement is influenced by the intensity of use. Cylist with the use of bicycles that are not necessarily a chance to crash by 80 per cent.

Based on the correlation test that has been done on the response variable and explanatory variable in the movement characteristics it is found that $\mathrm{X}_{15}$ (checking the brake condition), and $\mathrm{X}_{18}$ (wearing helmet) have an effect on the chance of the accident. There are two variables that proved significant that $\mathrm{X}_{15}$ and $\mathrm{X}_{18}$ then made a selection of variables that proved significant with the Backward Wald method. The value of regression coefficient (B) variable using helmet is -0.872 . This negative regression coefficient (B) means that the less wearing of the helmet the more likely the accident. The significance value of these variables less than 0.05 indicates that these variables significantly influence the response variable. As for the establishment of accident opportunities utility is formulated by:

$$
Z=1,253-1,060 X_{15}
$$

Prediction model of cyclist accident probability based on behavior aspects are:

$$
P_{(B A)}=\frac{1}{1+e^{-\left(1,253-1,060 x_{15}\right)}}
$$

Prediction model of cyclists' accidents probability based on behavior characteristics in the City of Malang is influenced by $\mathrm{X}_{15}$ (checking the bicycle brake).

Example calculation:

$$
P_{(B A)}=\frac{1}{1+1+e^{-(1,253-1,060(0))}}=0,548
$$

Based on the example can be interpreted if the chance of cyclists' accident in Malang based on behavioral characteristics influenced by the behavior when driving is checking the condition of the bicycle brake. Cyclist who drive while not checking the brake condition have the chance to crash by 54.8 per cent.

\section{Conclusion}

The results showed that the majority of cyclist in the city of Malang had an accident while cycling. The prediction model of cyclists' accidents involving cyclist in the City of Malang was formulated with $P_{(B A)}=\frac{1}{1+e^{-\left(-1,047+1,103 x_{3}+1,617 x_{6}-1,965 x_{15}+2,029 x_{16}+1,057 x_{24}\right)}}$ with $\mathrm{X}_{3}=$ income, $\mathrm{X}_{6}=$ ownership of bicycle, $\mathrm{X}_{15}=$ behavior of check the brakes, $\mathrm{X}_{16}=$ behavior of check the tires, and $\mathrm{X}_{24}=$ cycling in groups. 


\section{Acknowledgements}

Special thanks to all member of Transportation Laboratory Department of Civil Engineering, EIIS Laboratory of Department of Urban and Regional Planning, Engineering Faculty, Brawijaya University for their support and kindly help to this research, especially for Debi and Rizaldy and all of Bicycle Research Team that we can not mention one by one, Thank you very much.

\section{References}

1. Republic of Indonesia. Law of the Republic of Indonesia No.22 of 2009 on Traffic and Transportation. (2009)

2. Warpani. Management of Traffic and Road Transport. Bandung: ITB. (1999)

3. East Java Police. Traffic Accident Data: http://korlantas.info

4. Patriya, Rukma Nur. Characteristics of Motorcycle Users in Malang City. Thesis Not Published. Malang: Universitas Brawijaya. (2008)

5. Tamin, Ofyar Z. Transport Planning and Modeling. Bandung: ITB Bandung. (2000)

6. Khisty, C. Jhotin, and Lall, B. Kent. Fundamentals of Transport Engineering. Bandung: Erland. (2003)

7. Sulistio et al, Harnen. Motorcycle Accident Model On A Road. Malang: Universitas Brawijaya. (2010)

8. Central Bureau of Statistics of Malang. Malang City In Figures 2016. Malang: Central Bureau of Statistics. (2016) 